\title{
The Synergism of STM and the Effectiveness of Simultaneous Interpreting
}

\author{
Kang Zhifeng $^{1}$, Duan Jihong ${ }^{2}$ \\ ${ }^{1}$ College of Foreign Languages and Literatures, Fudan University, Shanghai, China \\ ${ }^{2}$ Department of Languages and Literatures, Shijiazhuang Preschool Normal College, Shijiazhuang, China
}

\section{Email address:}

kangzhifeng@fudan.edu.cn (Kang Zhifeng), dora1990@qq.com (Duan Jihong)

\section{To cite this article:}

Kang Zhifeng, Duan Jihong. The Synergism of STM and the Effectiveness of Simultaneous Interpreting. International Journal of Language and Linguistics. Vol. 3, No. 6, 2015, pp. 341-346. doi: 10.11648/j.ij11.20150306.14

\begin{abstract}
STM is the abbreviated form of short-term memory that consciously processes the information in interpreting. As both a buffer and a processor, STM plays an indispensable part in interpreting practices. This study, through live simultaneous interpreting (SI) experiments and observations to the MTI that the researcher has taught in the SI classroom in the College of Foreign Languages and Literatures at Fudan University, analyzes their STM abilities to do SI. The results of experimental research show that the function of STM is increasingly prominent; and moreover, the STM synergism strategy is conducive to enhancing the timeliness and the ten-dimensions of student interpreters in their SI, which consequently expedites the effectiveness.
\end{abstract}

Keywords: STM, Synergism, Simultaneous Interpreting, Timeliness, Effectiveness

\section{Introduction}

Cognitive psychologists generally believe that the primary procedures of memory consist of three aspects: encoding, storage and retrieval (Xu, 2008:17). These three aspects are closely interrelated with one another. Concretely, information firstly enters short term memory (STM) in the form of sounds encoding. Meanwhile, priming effect occurred to activate the semantic information stored in long term memory (LTM). Thereafter the activated semantic information will temporarily be stored in working memory (WM) and eventually be transformed to LTM by rehearsal. According to the theory of Levels-of-Processing Framework (Nordhielm, 2002: 371-382/2003: 91-104), the levels of information storage largely depend on the encoded information. Just as the information in computers needs to be artificially classified and put into separate files so as to be retrieved later, information encoding rearranges and assembles messy information in brains to save more memory storage space (Sternberg, 2003). During the whole memory process of simultaneous interpreting (SI) from source language (SL) to target language (TL) (Kang, 2011: 81), information encoding determines success or failure of SI memory (ibid, 2013:30). However, information encoding is not a single link, but includes information option and encoding. Therefore, from super-lingual (ibid, 2012: 106) information option to encoding, the function of STM is more prominent. Only by developing synergism of STM can the effectiveness of SI be enhanced.

\section{Definition Construal of STM}

STM is short-term memory, which refers to a few seconds or minutes' retention after memory experience, or information capacity that can be identified and recalled within a few seconds or minutes. External stimulative information activates sense memory through sense channel, then comes into STM. STM is "a buffer and a processor with finite capacity before information comes to long term memory (LTM), and the only memory phase where information is processed consciously. Therefore, STM includes not only two short-term memorizers _ visual and spatial memorizers, but also the central executive which processes limited data and controls the whole system. (Gui, 2002: 48-49)"

\section{Functional Validity of STM}

If we regard interpreters as a bridge between speakers of SL and listeners of TL, STM is just as a link that connects the encoding of decoded SL information input with the retrieved 
TL information. Therefore, a good ability of STM is a prerequisite for interpreters to perform excellently during interpreting.

While talking about the qualifications of interpreters, Phelan (Phelan, 2001:4-5) stated, "interpreters need to have good STM ability to store the information he/she hears...". During the interpreting memory phase, interpreters hence need have good STM ability to encode, store and retrieve the decoded information from SL; During the phase of interpreting expression, if interpreters do not have good STM ability and cannot timely retrieve the activated semantic information temporarily stored in WM, all of the efforts will be completely ruined and eventually result in invalid interpreting.

\section{Prominent Features of STM}

1) Selectivity of information in STM: In the course of interpreting when thousands of SL information swarms into interpreter' brains in a minute and comes into sense registration, the interpreter, if receiving all the information without filtration, will certainly fall into utter confusion and cannot accomplish interpreting task successfully. Given this, interpreters should give full play to the attention mechanism of brain which makes interpreters pay attention selectively so as to absorb valuable and meaningful information into STM and keep meaningless and valueless information away from attention. In other words, in the process of information transfer, interpreters should consciously select information for STM by attention control and interrupting information rejection. Despite the difficulty of interrupting information avoidance, at least by attention it can be reduced to the lowest. This is exactly an effective information selection in STM.

2) Instantaneity of information storage in STM: During the process when information comes into sense registration and STM, some unnoticed valueless or meaningless information is lost, while the noticed information is stored into STM through sense registration. Nevertheless, the information stored in STM cannot last long, generally 20 seconds, or above 20 seconds if the time of attention is added. It can thus be seen that STM has very strong instantaneity.

3) Finiteness of capacity in STM: Without rehearsal, information is usually composed of $7 \pm 2$ chunkings in STM, while any delay or interruption may reduce the capacity of STM from 7 to 3 (Miller, 1956: 81-97). Chunking items can be letters, numbers, words or sense groups; however, no matter what kind of chunking it is, the capacity of STM generally remains $7 \pm 2$ chunkings (ibid.).

4) Fluxility of information in STM: Information in STM has very strong fluxility. This means the Central Processing Unit (CPU) of human brain will deal with the information in STM that stays a very short period of time at the fastest speed, and keep it in LTM afterwards.

5) Deviation of information encoding in STM: In terms of Conrad's theory (1964), the encoding form of STM is auditory encoding. When stimulus information is presented in a visual way, people also process the information by simplifying or transferring them into auditory code that can be encoded by STM. In STM, the input stimulus information primarily encodes the information in the way of verbally auditory codes. Based on the experiment of Posner, Boies, Eichelman, Taylor et al. (1969), visual encoding is also one of the ways for information encoding in STM. According to Wickens' experimental theory of semantic encoding (1970, 1972, 1973), semantic encoding as one of the encoding forms is a kind of encoding that relates to meanings without the features of sensory channel. That semantic encoding exists in STM is proved by Wickens' experiment (ibid.) and the experiment results have widely been applied in the domain of cognitive psychology. Hence, STM has visual encoding and semantic encoding as well as the deviation of auditory encoding.

In short, STM serves as the preparation for successfully outputting information. In order to smoothly output information and accomplish interpreting products, the key is to convert the received speech sounds information into semantic form encoding. In other words, the speech sounds information in STM must exert activating effect promptly and activate the corresponding semantic information stored in LTM. Once activating effect cannot be carried out instantly, speech sounds information will disappear swiftly.

Table 1. Tracking Experiments to MTI for burrowing their STM Ablation Rate.

\begin{tabular}{|c|c|c|c|c|c|c|}
\hline \multicolumn{3}{|l|}{ Items } & Week 1 & Week 3 & Week 5 & Week 8 \\
\hline \multicolumn{3}{|c|}{ No. of participants } & 28 & 28 & 27 (1 absent) & 27 (1 absent) \\
\hline \multicolumn{3}{|c|}{ STM Ablation Rate (\%) (E-C) } & 54.917 & 48.226 & 41.651 & 40.286 \\
\hline \multicolumn{3}{|c|}{ STM Ablation Rate (\%) (C-E) } & 42.592 & 40.775 & 39.349 & 38.613 \\
\hline \multirow{10}{*}{ Problems } & \multirow{2}{*}{ Attention } & No. & 16 & 15 & 13 & 10 \\
\hline & & Ratio & 57.143 & 53.571 & 48.148 & 37.037 \\
\hline & \multirow{2}{*}{ concentration } & No. & 19 & 17 & 17 & 16 \\
\hline & & Ratio & 67.857 & 60.714 & 62.963 & 59.259 \\
\hline & \multirow{2}{*}{ Selection } & No. & 25 & 24 & 22 & 22 \\
\hline & & Ratio & 89.286 & 85.714 & 81.482 & 81.482 \\
\hline & \multirow{2}{*}{ Capacity } & No. & 23 & 23 & 22 & 20 \\
\hline & & Ratio & 82.143 & 82.143 & 81.482 & 74.074 \\
\hline & \multirow{2}{*}{ Encoding } & No. & 22 & 20 & 20 & 18 \\
\hline & & Ratio & 78.571 & 71.429 & 74.074 & 66.667 \\
\hline
\end{tabular}




\section{Live Experiment of STM}

This study, through live simultaneous interpreting (SI) experiments on STM and observations to the MTI that the researcher has taught in the SI classroom in the College of Foreign Languages and Literatures at Fudan University, explores the ablation rate of STM and the various problems occurring in the course of STM. The results are shown as below (Table 1):

Table 1 shows that the live experiment on STM is conducted four times. There are 28 participants in Week 1 and Week 3, and 27 in Week 5 and Week 8. Through the four tests of STM ablation rate among MTI E-C interpreters, the ablation rate in Week 8, though reduced by $14.631 \%$ compared with that in Week 1 , is $40.286 \%$. By contrast, the STM ablation rate among MTI C-E interpreters is relatively low. Despite that, the rate in Week 8 still reaches 38.613\%. Simultaneously, the results of questionnaires and SI effect test to MTI interpreters indicate that most student interpreters have problems in SL information attention, SL information concentration, SL information selection, SL information capacity and TL information encoding. Because of these problems, the research figures out the corresponding strategy of STM.

\section{Synergism Strategy of STM}

Based on the experimental results of STM, a series of interpreting STM strategies like information attention strategy, information concentration strategy, information selection strategy, information capacity strategy, information encoding strategy, STM training strategy etc. are adopted in terms of the prominent features of STM such as information selectivity of STM, information storage instantaneity of STM, capacity finiteness of STM, information fluxility of STM, information encoding deviation of STM/selectivity of information in STM, instantaneity of information in STM, Finiteness of capacity in STM, fluxility of information in STM, deviation of information encoding in STM and so on. They are helpful for interpreters, especially student interpreters, to master the skills of STM, enhance their interpreting memory and better accomplish interpreting tasks.

1) Information attention strategy: Interpreters, especially student interpreters should pay attention to speakers' or orators' information output. Only by implementing attention strategy can they understand speakers or orators' meaning of words, prepare for smooth selection of meaningful and valuable information, and thereby obtain effective information of SL.

2) Information concentration strategy: Information concentration strategy should come after information attention strategy. Interpreters are supposed to concentrate on speaker's or orator's chunking information and overall information rather than single word information, that is to say, interpreters should concentrate on listening to "meaning" instead of "words". As for interpreting beginners, they tend to make the mistake of not seeing the forest for the trees. After a speech, they only memorize some words without grasping the integrated meaning; hence it is of immense significance for interpreters to concentrate on the memory content.

3) Information selection strategy: When retrieving information, interpreters should selectively memorize conception, proposition, designation, number, and logic relation etc., namely the content with practical significance. Accordingly, quite a few scholars posed outline memory method that requires interpreters to memorize discourse structure and catch general ideas, so as to supplement corresponding content.

4) Information capacity strategy: It is a strategy that interpreters to greatest extent enlarge their storage capacity of STM to remember more information. Although the capacity of STM only has $7 \pm 2$ chunkings (Miller, 1956:81-97), the capacity of each item is not definitely restricted. A number of researchers hold that information capacity of STM can be expanded by enlarging information chunkings, while the capacity of chunkings can be expanded by information visualization and information logicalization. In short, the process of information chunking is just a course of establishing relationship between individual information. Furthermore, the closer the relationship between each information is, the better results of memory can be obtained (Li, 2004: 18-19; Zhang, 2007:50). While memorizing information through information visualization, interpreters should fully stimulate their imagination to make the images in brain as vivid as possible, for example.

[SL] As well as being the centre of Scottish government, located in the new Parliament building, Edinburgh is also the focal point for many of its cultural events. Every August, the east coast city is taken over by the world famous Edinburgh Festival, a month-long celebration of theatre, comedy, dance, books, music and film. Thousands of visitors including hundreds of performers take part in an arts extravaganza. In fact, it's not just one festival but many, including the official International Festival, the Festival Fringe, Book, Film and Art Festivals as well as many others, offering something for everyone. It becomes a badge of honor to sample as much variety as possible, taking in acrobatic acts followed by the premiere of a major new movie, or a challenging new theatre drama followed by a top stand-up comedian.

【TL】作为坐落在新国会大厦的苏格兰政府的中心所在 地，爱丁堡同时也是很多苏格兰文化活动的中心。每年八 月份, 其东海岸的城市就沉浸在著名的爱丁堡艺术节里了, 这是一个为期一个月的包括戏剧、喜剧、舞蹈、书籍、音 乐和电影的庆典。有成千上万的游客包括几百个表演者参 加到这个艺术盛典。事实上这不单只是一个节日, 而是一 个包括了官方国际节、戏剧节、图书节、电影节、艺术节 等众多节日的大杂烩, 每个人都能从中得到自己的乐趣。 爱丁堡艺术节已经成了一个荣誉的象征, 它尽可能地给人 们呈现出不同的色彩。比如在一部新的大制作电影首映礼 前我们能欣赏到杂技表演, 又比如在一个富有挑战性的新 
戏剧中, 我们会看到一个站得高高的喜剧演员在那尽情表 演。(Kang，2007)

When interpreters hear "Edinburgh is also the focal point for many of its cultural events. Every August, the east coast city is taken over by the world famous Edinburgh Festival, a month-long celebration of theatre, comedy, dance, books, music and film.", they immediately think of the bustling, vivid scenes of various art celebrations held in Scottish Art Centre, such as theatre, comedy, dance, books, music, film and so on. While these information chunkings which are related and close to one another, such as theatre, comedy, dance, books, music, film etc. all belong to cultural activities. Meanwhile, information expansion among these chunkings contributes to interpreters' STM; what is more, the processed information only takes up so small a space of STM as to relieve the pressure of STM greatly.

Visualization and lexicalization memory methods above differ in application scope. Visualization memory method applies to descriptive and narrative genre; nevertheless, logicalization memory method applies to exposition styles, for instance.

【SL】国务院总理李克强指出, 为使中美战略经济对话 发挥更加积极的作用, 双方应从以下几个方面做出努力: // 一是要从大处着眼、从长远出发, 讨论两国共同关注的 全局性、战略性、长期性的经济问题; /I 二是平等群商、 求同存异, 充分考虑彼此的关切; /I 三是以发展的眼光, 拓展利益交汇面, 实现互利共赢; // 四是加深了解, 增强 互信, 不断扩大共识。

[TL] Premier Li Keqiang of the State council pointed out that in order to enable the China-US dialogue to play a more active role, the two sides should make efforts on the following aspects. // Firstly, we should discuss the overall, strategic, and long-term economic issues, which both countries focus on, from key points and the long-term point of view. // Secondly, both countries should make consultation equally and seek for common ground, fully considering each concern. // Thirdly, we should broaden the interests' interface with developing point of view and achieve mutual benefit and win-win results. // The fourth point is to deepen understanding, enhance confidence between both sides, and continually expand consensus.

This is a very logical statement basically without any visualization. Logicalization memory method is applicable to such an exposition style, because this statement is clearly expressed from firstly to fourthly. This method helps to develop the mode of logical thinking and logical memory in interpreters' brain.

5) Information encoding strategy: As mentioned above, the information of STM mainly includes auditory encoding, but not excluding other encoding forms such as visual encoding and semantic encoding. No matter what form is adopted to encode the obtained information; the only goal is to prepare for successfully bringing information into LTM. This means that the speech sounds information of STM must achieve activating effect promptly and activate its corresponding semantic information stored in LTM.

Information selection and information encoding forms largely determine the success of information retrieval, so the tasks of STM can only be accomplished by implementing information encoding strategy, fully playing the function of auditory encoding and adopting both visual encoding and semantic encoding.

6) STM training strategy: Student interpreters should receive special training of STM attention, auditory sense, visual sense, and semantic encoding in the mode of SI. With the help of this training strategy, students can achieve good effectiveness of STM.

\section{Tracking Experiments of STM}

This research did a 15 -week tracking experiments on the MTI interpreters of 2014 taught by the researcher in College of Foreign Languages and Literatures, at Fudan University. The experiments in Week 1, Week 3, and Week 5 and from Week 10 to Week 15 took place in Classroom 5113 and Simultaneous Interpretation Laboratory 5207 in Classroom Building Five. The experiments continued five times, and for each SI time was limited to five minutes — starting timer as soon as the speakers began to read each text. Student interpreters rendered both E-C and C-E SI to test their ability of STM (see Table 2). The experimental contents were "The Secretary-General's Message on World Environment Day on June 5, 2011” and the speech “气候变化与中国” (Excerpt) addressed by Fu Ying, the Chinese ambassador, to UK in London School of Economics (LSE) and so on (Kang, 2013:108-110).

Table 2. Basic Situation of STM Experiments.

\begin{tabular}{llllll}
\hline Items & Week 1 & Week 3 & Week 5 & Week 10 & Week 15 \\
\hline Subjects & MTI & MTI & MTI & MTI & MTI \\
Places & Rm5113 & Rm5113 & Rm5113 & SL lab 5207 & Rm5113 \\
No. & 28 & 28 & 27 & 26 & 28 \\
Interpreting Models & SI & SI & SI & SI & SI \\
Language Models & E-C; C-E & E-C; C-E & E-C; C-E & E-C; C-E & E-C; C-E \\
& E-C: & E-C: & E-C: & E-C: & E-C: \\
Contents & Passage 1, Part I & Passage 1, Part II & Passage 1,Part III & Passage 1, Part IV Passage 1, Part V \\
& C-E: & C-E: & C-E: Passage 2, Part & C-E: Passage 2, C-E: Passage 2, Part \\
Difficulty & Passage 2, Part I & Passage 2, Part II & III & Part IV & V \\
\hline
\end{tabular}

*E-C: (interpreting) from English into Chinese; **C-E: (interpreting) from Chinese into English 
Table 2 illustrates the experimental subjects, places, numbers, interpreting models, language models, contents, and difficulty levels of interpreting products. Although the content in each experiment is different, the SPSS computed difficulty level is between 0.504 and 0.561 , with its mean value of 0.541 , almost the same. Five Tracking experiments were performed to assess the student interpreters' STM ability. Thereinto, no STM synergism strategy was implemented in Week 1, Week 3 or Week 5. Since Week 10, the STM synergism strategy began to take effect. The result is presented as follows (see Table 3 ).

Table 3. Effect Form of STM Output.

\begin{tabular}{lccccc}
\hline Items & Week 1 & Week 3 & Week 5 & Week 10 & Week 15 \\
\hline $\begin{array}{l}\text { E-C: SI } \\
\text { Average }\end{array}$ & 57.249 & 62.415 & 71.404 & 85.916 & 92.557 \\
$\begin{array}{l}\text { Accuracy (\%) } \\
\text { C-E: SI }\end{array}$ & & & & & \\
$\begin{array}{l}\text { Average } \\
\text { Accuracy (\%) }\end{array}$ & 55.082 & 59.318 & 64.220 & 80.348 & 89.161 \\
\hline
\end{tabular}

From Table3, it is found that the average accuracy of SI has no obvious difference from Week 1 to Week 3, regardless of E-C interpreting or C-E interpreting. The average accuracy of E-C SI rises to $62.415 \%$ from $57.249 \%$, growing by $5.166 \%$, and that of C-E SI rises to $59.318 \%$ from $55.082 \%$, growing by $4.263 \%$. These two items above do not show sharp amount of growth. Although growth is sustained at Week 5, the amount of growth is still not apparent. However, in Week 10, due to the application of synergism strategy of STM, the amount of growth rises by $28.667 \%$ compared with Week 1 and by $14.512 \%$ compared with Week 5 , which indicates a considerately large increase. In Week 15, the average accuracy of SI of each item still goes up greatly (see Figure 1).

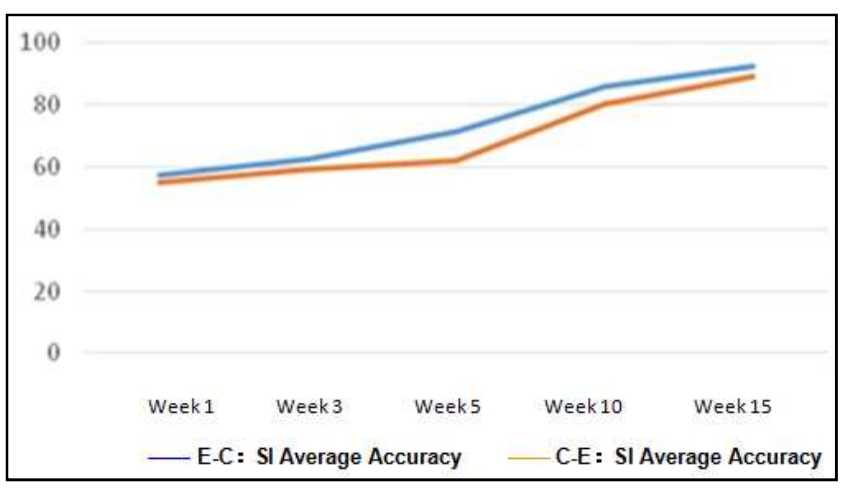

Figure 1. SI Accuracy under STM Strategy.

Figure 1 clearly shows the variation of STM ability increase of MTI interpreters with incrementing time of professional training of SI in 15 weeks. Especially after implementing synergism strategy of STM, the increase in Week 10 reached its highest.

In view of the tracking experiments above, the acquired data has been processed by SPSS to identify its significance, reliability, and validity. The results are shown below (see Table $4 \& 5$ ).

T-TEST

/TESTVAL $=0$

$/ \mathrm{MISSING}=$ ANALYSIS

/VARIABLES=VAR00001 VAR00002

/CRITERIA=SI(.95).

Table 4. Analyses of SI Accuracy Mean of STM Output.

\begin{tabular}{lllll}
\hline Items & $\mathbf{N}$ & Mean & Std. Deviation & Std. Error Mean \\
\hline $\begin{array}{l}\text { VAR00001 } \\
\begin{array}{l}\text { (E-C:SI) } \\
\text { VAR00002 }\end{array}\end{array}$ & 5 & 73.9538 & 15.02460 & 6.71921 \\
\begin{tabular}{l} 
(C-E:SI) \\
\hline
\end{tabular} & 5 & 69.6256 & 14.52280 & 6.49479 \\
\hline
\end{tabular}

Table 5. Testing Sample of SI Accuracy of STM Output.

\begin{tabular}{|c|c|c|c|c|c|c|}
\hline \multirow{3}{*}{ Items } & \multicolumn{6}{|c|}{ Testing Value $=0$} \\
\hline & \multirow{2}{*}{$\mathbf{t}$} & \multirow{2}{*}{ df } & \multirow{2}{*}{ Sig. (2-tailed) } & \multirow{2}{*}{ Mean Value-Different Value } & \multicolumn{2}{|c|}{$95 \%$ Confidence Interval of the Difference } \\
\hline & & & & & Lower & Upper \\
\hline VAR00001(E-C:SI) & 11.006 & 4 & .000 & 73.95380 & 55.2983 & 92.6093 \\
\hline VAR00002(C-E:SI) & 10.720 & 4 & .000 & 69.62560 & 51.5932 & 87.6580 \\
\hline
\end{tabular}

Table 4 shows that the accuracy mean of E-C SI is 73.9538 , that of C-E SI is 69.6256, and the standard deviations are 15.02460 and 14.52280 . Table 5 indicates that $P$ value is .000 $<.001$, which proves this experiment is of considerable significance.

RELIABILITY

/VARIABLES=VAR00001 VAR00002

/SCALE('ALL VARIABLES') ALL

$/ \mathrm{MODEL}=\mathrm{ALPHA}$.

Table 6. Case Summary of SI Accuracy of STM Output.

\begin{tabular}{llll}
\hline Items & & $\mathbf{N}$ & $\mathbf{\%}$ \\
\hline \multirow{4}{*}{ Case } & Valid & 5 & 100.0 \\
& Excluded & 0 & 0 \\
& Total & 5 & 100.0 \\
\hline
\end{tabular}

Table 7. Reliability of STM Ability Experiment Statistics.

\begin{tabular}{ll}
\hline Cronbach's Alpha & Items \\
\hline .995 & 2 \\
\hline
\end{tabular}

From the data listed in Table 6 , it is found that five experiments are performed and their effective rate is $100 \%$. Table 7 indicates that Cronbach's Alpha is .995, which shows that the experiment is very reliable.

CORRELATIONS

/VARIABLES=VAR00001 VAR00002

/PRINT=TWOTAIL NOSIG

/MISSING=PAIRWISE. 
Table 8. Correlation Experiment Statistics.

\begin{tabular}{llll}
\hline Items & & VAR00001 & VAR00002 \\
\hline \multirow{2}{*}{ VAR00001(E-C: } & Pearson Correlation & 1 & $.991^{* *}$ \\
SI) & Sig. (two-tailed) & & .001 \\
& $\mathrm{~N}$ & 5 & 5 \\
VAR00002(C-E: & Pearson Correlation & $.991^{* *}$ & 1 \\
SI) & Sig. (two-tailed) & .001 & \\
**. Correlation is significant at the .01 level (2-tailed). & \\
\hline
\end{tabular}

As revealed in Table 8, the Pearson correlation is .991, which indicates the significance of the two-tailed correlation, in other words, being significantly correlated at .01 level (two-tailed).

Given all the above, this tracking experiment is not only significant (.000) but also highly reliable (.995) and valid $(100 \%)$. The function of STM becomes more prominent when synergism strategy of STM is applied to student interpreters' SI. For student interpreters, the crux of SI memory training, especially the training of STM, is firstly to learn to grasp the meaning of information as a whole and cultivate their ability of promptly sorting out the logical outlines of discourses; and secondly to fully exert student interpreters' spatial imagination and enlarge memory contents of similar information in chunkings. Interpreters' spatial imagination plays a vital role in memorizing descriptive and logical discourses. Regardless of the logical analyses of discourses or the formation of vivid pictures, all these information processing, information encoding require to be accomplished instantaneously. Information encoding, including auditory encoding, sound image encoding, visual encoding and semantic encoding, determines information retrieval. Hence, the methodization and visualization of information in the brain, as well as the effective role of synergism strategy of STM, is conducive to making the effectiveness of SI more obvious.

\section{Conclusion}

The characteristics of STM and interpreting reflect the intimate relationship between STM and interpreting. Interpreting fails to be rendered without STM and effective STM helps to benefit interpreting. MTI interpreters have problems in attention, concentration, selection, capacity and encoding during SI practices. For this reason, introducing synergism strategy of STM in professional training can promote the achievement of better performance in SI timeliness, ten-dimensions and effectiveness.

\section{References}

[1] Atkinson, R. C. \& R. M. Shiffrin. (1968). Human Memory: A Proposed System and Its Control Processes [A]. In K. W. Spence and J. T. Spence (Eds.), The Psychology of Learning and Motivation $[\mathrm{C}]$, vol. 8. London: Academic Press.

[2] Conrad, R. (1964). Acoustic Confusions in Immediate Memory [J]. British Journal of Psychology, 55: 75-84.
[3] Gile, D. (1995). Basic Concepts and Models for Interpreter and Translator Training [M]. Amsterdam/ Philadelphia: John Benjamins.

[4] Gui, S. C. (2002). Psycholinguistics (New Edition) [M]. Shanghai: Shanghai Foreign Language Education Press. 48-49.

[5] James, W. (1890). The Principles of Psychology [M]. Vols. 1 \& 2. New York: Henry Holt, 403-404.

[6] Kang, Z. H. (2007). Interpreting Theory and Practice Skills [M]. Shanghai: East China University of Science and Technology Press. 3, 71-93, 122.

[7] Kang, Z. H. (2011). Consecutive Interpreting and "AA+EA" Strategy [J]. Foreign Language Learning Theory and Practice. 143(2): 81.

[8] Kang, Z. H. (2012). Interpreting Anxiety with Multimodalities: The Sources of Degrees [J]. Foreign Language Education. 33(3): 106 .

[9] Kang, Z. H. (2013). Cognitive Psychology of Interpretation [M]. Beijing Yanshan Press. 30.

[10] Li, F. Q. (2004). Theory of interpreting memory strategies/ Strategies for Memory Retention in Interpretation [J]. Chinese Science \& Technology Translators Journal. (4): 18-19.

[11] Miller, G. A. (1956). The Magical Number Seven, Plus or Minus Two: Some Limits on Our Capacity for Processing Information [J]. Psychological Review, 63: 81-97.

[12] Nordhielm, C. (2002). The influence of level of processing on advertising repetition effects [J]. Journal of Consumer Research, 29: 371-382.

[13] Nordhielm, C. (2003). A levels-of-processing model of advertising repetition effects [A]. In L. M. Scott \& R. Batra (Eds.), Persuasive Imagery: A Consumer Response Perspective [C]. Mahwah, NJ: Lawrence Erlbaum Associates. 91-104.

[14] Phelan, M. (2001). The Interpreter's Resource [M]. UK: Frankfurt Lodge, Clevedon Hall, Victoria Road, Clevedon BS21 7HH. Printed and Bound in Great Britain by the Cromwell Press Ltd. 4-5.

[15] Posner, M. I., Boies, S. J., Eichelman, W. H. \& R. L. Taylor. (1969). Retention of Visual and Name Codes of Single Letters [Monograph] [J]. Journal of Experimental Psychology, 79: 353-363.

[16] Sternberg, R. J. (2003). Cognitive Psychology [M]. Translated by Yang Bingjun et al. (2006) China Light Industry Press. 119.

[17] Wickens, D. D. (1970). Encoding Categories of Words: An Empirical Approach to Meaning [J]. Psychological Review, 77: $1-15$.

[18] Wickens, D. D. (1972). Characteristics of Word Encoding [A]. In A. Melton \& E. Martin (Eds.), Coding Processes in Human Memory [C], Washington, D. C.: Winston. 191-215.

[19] Wickens, D. D. (1973). Some Characteristics of Word Encoding [J]. Memory and Cognition, (1): 485-490.

[20] Xu, M. (2008). Cognitive Researches on Interpretation in the West: An Overview [J]. Chinese Translators Journal. (1): 17 .

[21] Zhang, J. L. (2007). Short-term Memory Training in Consecutive Interpreting Based on Cognitive Psychology [J]. Journal of Shenyang Normal University (Social Science Edition), (5):50. 